\title{
Exosomes as mediators of neuroinflammation
}

\author{
Archana Gupta ${ }^{1,2}$ and Lynn Pulliam ${ }^{2^{*}}$
}

\begin{abstract}
Exosomes are membrane-bound nanovesicles that are shed by cells of various lineages under normal as well as pathological conditions. Previously thought to be 'extracellular debris', exosomes have recently generated immense interest following their discovery as mediators of intercellular communication by delivering functional proteins, mRNA transcripts as well as miRNAs to recipient cells. Although suggested to primarily serve as signaling organelles which also remove unwanted cellular components in the brain, accumulating evidence suggests that exosomes can also significantly contribute to the development of several neuropathologies. Toxic forms of aggregated proteins such as $\alpha$-synuclein, amyloid $\beta$ and prions, that are responsible for the development of Parkinson's disease, Alzheimer's disease and Creutzfeldt-Jacob disease (CJD) respectively, have been shown to get effectively packaged into exosomes and spread from one cell to another, initiating an inflammatory cascade. In addition, exosomes secreted by resident brain cells in response to pathogenic stimuli such as viral proteins can also influence bystander cells by the transfer of dysregulated miRNAs that suppress the expression of essential genes in the recipient cells. Given the relevance of exosomes in brain communication and neuropathogenesis, novel therapeutic strategies are now being developed that exploit the biology of these vesicles to deliver anti-inflammatory molecules to the CNS. Exosomes may alter the way we think about brain disorders and their treatments.
\end{abstract}

Keywords: Exosomes, Monocytes, Neuroinflammation, CNS

\section{Introduction}

Disorders of the central nervous system (CNS) can arise from a variety of etiologies including neurodegeneration, autoimmunity and infection. Although several mechanisms have been implicated, one common player capable of mediating the pathogenesis of these diseases has recently emerged. Exosomes are spherical, membrane-bound nanovesicles that are shed by a majority of cell types in the body. They are released under normal as well as pathological conditions and mediate intercellular communication between cells of various lineages. Initially thought to be waste bags that carried unwanted proteins shed by cells, exosomes were only recently discovered to contain not only cellular proteins but also mRNA transcripts as well as miRNA from the host cell. Importantly, exosomes can to be internalized by cells of various lineages and functionally alter the physiological environment of the recipient cell. These observations quickly changed the perception of exosomes from organelles carrying cell debris to messengers

\footnotetext{
* Correspondence: Lynn.pulliam@ucsf.edu

${ }^{2}$ Departments of Laboratory Medicine and Medicine, San Francisco and Veterans Affairs Medical Center, University of California, 4150 Clement St (113A), San Francisco, CA 94121, USA

Full list of author information is available at the end of the article
}

for cell communication. The past few years have witnessed a deluge of information in the field of extracellular vesicles and their implications to not only serve as potential biomarkers of several diseases, but also as a mechanism for the development of many pathological conditions. The information unraveled thus far is just the tip of the iceberg. The discovery of exosomes as extracellular vesicles packed with functional cellular cargo bears the potential to significantly influence the future of diagnostics and drug delivery. This review focuses on the current knowledge of exosomes in the pathogenesis of various CNS disorders, their potential to serve as therapeutic agents to treat neuroinflammation as well as biomarkers to diagnose various brain diseases.

\section{Exosome biogenesis}

Exosomes are 30 to $100 \mathrm{~nm}$ spherical vesicles that are released in to the extracellular space by diverse cell types and mediate a variety of cellular functions $[1,2]$. Similar to microvesicles, exosomes also transport a host of biomolecules to cells of different lineages [3-7]. Together, they are often referred to as extracellular vesicles and can be distinguished not only by their size, but also by 
the source of their origin. In contrast to microvesicles that are shed by the plasma membrane $[7,8]$, exosomes are formed by the inward budding of the limiting membrane of the late endosome, and encapsulate cellular proteins, RNA as well as miRNAs from the cytoplasm in a non-random fashion $[9,10]$. Late endosomes that are packed with several such small vesicles (or intraluminal vesicles) are often termed multivesicular bodies (MVBs). The late endosomes are destined to either fuse with the lysosome which leads to the degradation of the contents of the vesicles, or the plasma membrane which allows for the exosomes to be released into the extracellular space. The formation of the intraluminal vesicles is a regulated process that involves the organization of the endosomal membrane into specialized domains that are highly enriched for a specific class of membrane proteins called tetraspanins (Figure 1). These units, also called Tetraspanin-Enriched Membrane Domains (TEMs) recruit proteins required to facilitate vesicular fusion and/ or fission [11]. Additionally, the TEMs also recruit potential ligands for receptor-mediated internalization of the exosome by the recipient cell [12]. Several members of the tetraspanin family including CD9, CD63 and CD81 are highly enriched on exosomal membranes and not surprisingly, serve as marker proteins for the vesicles. A second set of proteins involved in the formation of the exosomes are the components of the ESCRT machinery (Endosomal Sorting Complex Required for Transport). Membrane proteins that are signaling-induced ubiquitinated and internalized into early endosomes trigger the recruitment of the ESCRT complexes. ESCRT complexes 0 , I, and II directly bind to ubiquitin, and therefore, allow only those proteins that are ubiquitinated to be loaded onto MVBs. However, there are a few exceptions in which proteins that are not ubiquitinated are also sorted into these vesicles; in such instances, sorting is believed to be a passenger effect [13].

In addition, ESCRT I, and II are suggested to drive the budding of the intraluminal vesicles (ILV), while ESCRT III is required for the cleavage of the bud to form the ILV. Another important protein, Alix, that is also often used as an exosomal marker and interacts with TSG101 and CHMP4, participates in several processes of the exosome biogenesis including cargo packaging and vesicle formation.

\section{Composition of exosomes}

Exosomes are lipid-bilayer enclosed vesicles that carry cellular proteins, mRNA as well as miRNAs. The membrane proteins appear in the same orientation as on the cell membrane, owing to two invaginations, one at the surface of the plasma membrane, during the formation

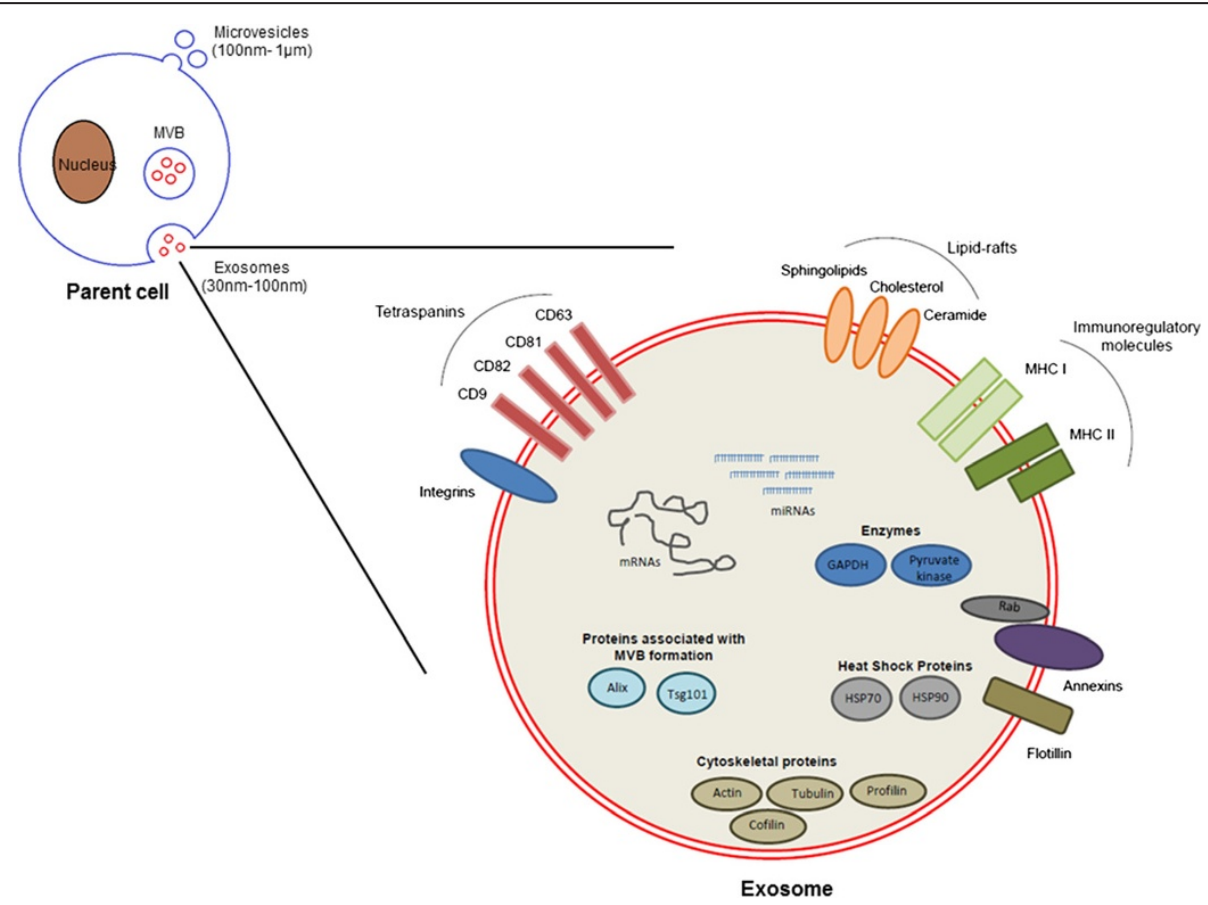

Figure 1 Composition of exosomes. Exosomes and microvesicles are membrane-bound extracellular vesicles secreted from various cell types. Exosomes are 30 to $100 \mathrm{~nm}$ in size and packed with a variety of cellular components including mRNAs, miRNAs and proteins that are often selectively packaged from the cell the vesicles are shed. The exosome membrane is decorated with various proteins involved in antigen presentation called major histocompatibility complexes ( $\mathrm{MHC}$ I and II), targeting and adhesion (integrins and tetraspanins), membrane trafficking (annexins and Rab proteins) as well as lipid-rafts. 
of the endosome, and the second by the inward budding of the endosomal membrane. Considering that the formation of exosomes is an active process, there are several membrane proteins and lipids that are unique to these vesicles compared to the cell surface. Owing to their endosomal origin, exosomes harbor tetraspanins (CD9, CD63, CD81 and CD82), proteins required for membrane transport and fusion (annexins, Rab proteins, flotillin), proteins associated with MVB biogenesis (Alix, TSG101), and heat shock proteins (Hsc70, Hsp90) as previously reviewed $[8,14]$ (Figure 1 ). The vesicles also carry a variety of cytoskeletal proteins (actin, tubulin, profilin, cofilin, and so on) and metabolic enzymes (GAPDH and pyruvate kinase). Additionally, the exosomal membrane is enriched with lipid-rafts including cholesterol, sphingolipids, ceramide and glycerophospholipids containing long and saturated fatty-acyl chains. Interestingly, exosomes secreted from antigen-presenting cells such as dendritic cells also exhibit functional major histocompatibility complexes (MHC I and II) on their surface $[15,16]$.

The cell type the exosome is derived from heavily influences the protein content of the exosomes. Several proteomic studies performed on exosomes isolated from cancerous cells reveal the presence of various factors associated with tumor progression such as metastasis, angiogenesis and signal transduction [17]. The exosomal pathway can also be hijacked by viruses to spread viral proteins to other cell types, without actually infecting them, and dysregulating their function. For instance, CD4+ T cells infected by HIV release the viral protein $\mathrm{Nef}$ in exosomes which induces apoptosis of bystander T cells [18].

Exosomes are highly enriched in small RNAs. A bioanalyzer profile of exosomal RNA indicates that the predominant RNA species in these vesicles ranges from 4 to 40 nucleotides in length [19], consistent with miRNAs. An increasing body of evidence suggests that exosomal miRNA is functional in the recipient cell and can repress the expression of the target genes in the latter [4,20-22]. The ability of such miRNAs to exert a biological effect indicates that they are stable as well as associated with cellular proteins that render them functional. Several studies show that exosomal miRNAs are in fact associated with Ago2 proteins, albeit to various degrees [23]. MVBs are proposed to be a site for the congregation of miRNA pathway components, mature miRNAs as well as the target transcripts [24], and may therefore be the route for the packaging of these elements into exosomes. Apart from cellular miRNAs, specific virus-encoded miRNAs can also be packaged into exosomes of infected cells. Epstein-Barr virus (EBV) has been shown to encode viral miRNAs BHRF1 and BART that can be shed in nanovesicles from infected B-cells and suppress the immunoregulatory gene CXCL11 in non-infected neighboring monocyte-derived dendritic cells [25]. In addition, HIV-encoded trans-activation response element (TAR)-miRNA can be released by infected cells in nanovesicles, influencing the susceptibility to infection of cells that internalize it [26]. Clearly, viruses have evolved strategies to usurp the host exosomal machinery in order to propagate and attenuate host antiviral response.

mRNA transcripts, also enclosed in exosomes, can be readily translated to proteins by the cell receiving the vesicles. Valadi et al. [27] were among the first to demonstrate that exosomal mRNA from mouse cells could be translated into murine proteins by human mast cells. However, the majority of these transcripts appear to be highly enriched in the 3 '-untranslated regions, suggesting that the mRNA in these vesicles may play more of a regulatory rather than a functional role [28].

Uptake of exosomes is an energy-dependent active process $[4,29]$. Various proteins and lipids present on the exosomal membrane such as tetraspanins and phosphatidylserine take part in receptor-mediated endocytosis by interacting with their complementary molecules present on the plasma membrane of the target cell $[29,30]$ and initiate internalization. The endocytic pathway involved in exosomal uptake however varies from cell-to-cell. Although phagocytosis is the major pathway for exosome internalization by professional phagocytic cells such as liver Kupffer cells and dendritic cells [30,31], uptake of vesicles by macropinocytosis has also been demonstrated for the brain resident macrophages, microglia [32]. In contrast, non-phagocytic cells employ both clathrindependent [29] and independent endocytic pathways [33] to internalize exosomes.

\section{Exosomes in CNS communication}

Most cells in the CNS, including neurons, astrocytes, oligodendrocytes and microglia shed exosomes. These extracellular vesicles are secreted by neural cells under both normal and pathological conditions and have been isolated not just from the cerebrospinal fluid [34] but also from adult human brain [35]. The suggested roles of exosomes in CNS are to get rid of waste membrane and cellular materials, and to serve as messengers for communication between neural cells. In that regard, exosomes can participate not only in the development of the CNS, but also in regulating synaptic activity as well as regeneration following injury. For instance, maturing neurons regulate oligodendrocyte differentiation by exerting an effect on the release of oligodendrocyte-derived autoinhibitory exosomes [36]. In contrast, exosomes released from oligodendrocytes in response to glutamate activation can influence neuronal metabolism and exhibit neuroprotective function by the functional transfer of oligodendrocyte cargo [37]. 
Synapses are essential to the function of neurons. They enable signal transduction from one neuron to the next by the transfer of chemical messages, inducing changes in second messengers that trigger a response leading to transmission of the signal. Exosomes shed by different neural cells can participate in synaptic excitation by transferring essential proteins for neurotransmission to neurons. Synapsin, a synaptic vesicle-associated protein implicated in neural development was shown to be released by glial cells in exosomes under conditions of high neuronal activity or cell stress [38]. These exosomes increase neuronal survival and promote neurite growth under adverse environmental conditions. Microglial cells can also stimulate synaptic activity in neurons via exosomes [39]. Microglial exosomes enhance ceramide and sphingosine metabolism in the recipient neurons resulting in an increase in neurotransmission.

Exosomes can mediate neuroprotection. Astrocytes, known primarily to provide nutritional support to neurons, secrete elevated levels of heat shock protein 70 (Hsp70) in response to oxidative stress and hyperthermia [40] by increasing the survivability of neighboring neurons during injury [41]. In the peripheral nervous system, Schwann cells communicate with and support axonal regeneration after nerve damage through exosomes. The exosomes mediate such effect, at least in part by the suppression of the activity of RhoA, a GTPase activated in response to injury and inhibiting axonal regeneration at growth cones [42] (Figure 2).

\section{Exosomes and neuroinflammatory disorders}

While exosomes mediate several vital processes required for normal brain functioning $[37,39,42]$, they are also involved in the pathogenesis of many neuroinflammatory disorders, both infectious [20,43] and neurodegenerative in nature [44-46]. Increasing evidence suggests that exosomes serve as carriers to misfolded and pathogenic proteins $[43,47]$, initiating or propagating the disease in neighboring cells. In addition to cytoplasmic proteins, aberrantly expressed cellular miRNAs, selectively packaged and transported in exosomes to neural cells [19,35], can further dysregulate gene expression of the recipient cell.

\section{Exosomes in the pathogenesis of infectious CNS diseases HIV-associated neurocognitive disorders (HAND)} HIV infection is associated with an elevated risk for neurological impairment. Abuse of drugs such as opiates during infection further increases the incidence and progression of HIV-associated neurodysfunction, although the mechanism for the synergistic effect remains unknown. A recent study by $\mathrm{Hu}$ et al. [20] suggested that co-exposure of astrocytes to morphine and HIV Tat

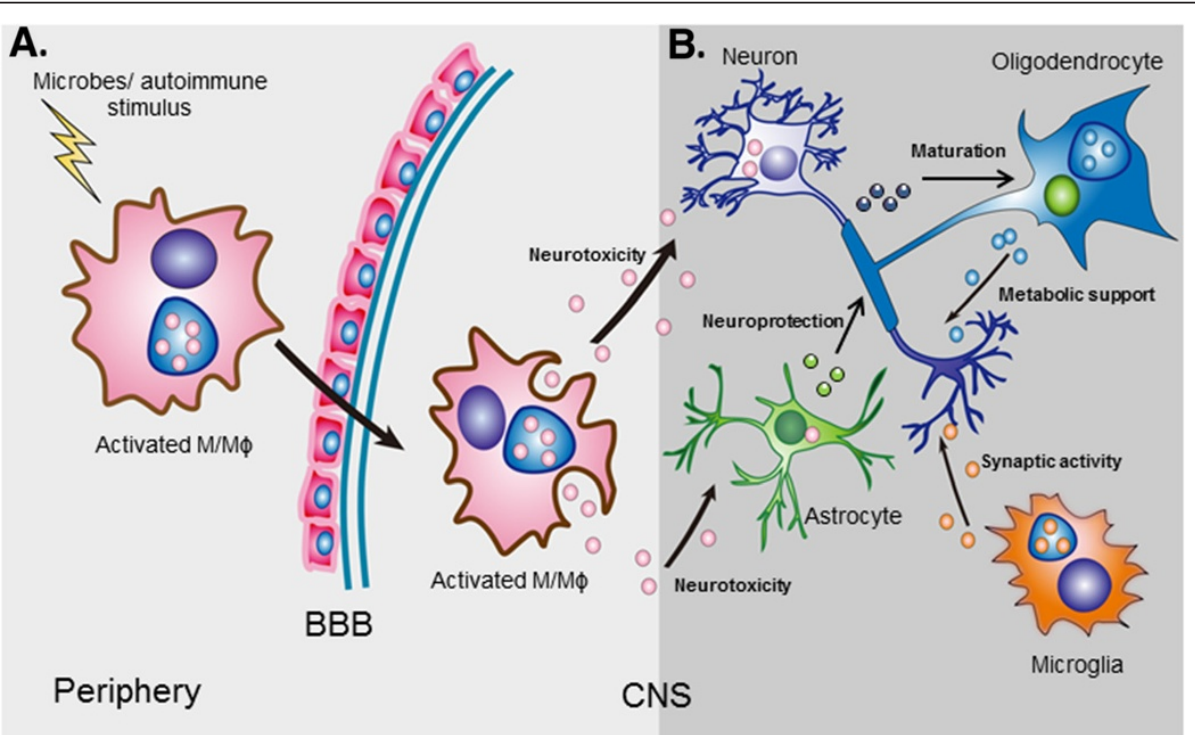

Figure 2 Exosomal cross talk from the periphery and within the central nervous system (CNS). (A) Influence of peripheral inflammation. Inflammation in the periphery can lead to neural cell impairment by virtue of activated monocyte-derived exosomes. Activated monocyte/ macrophages traffic across the blood-brain barrier (BBB) at a high frequency and shed exosomes that can harbor pathogenic cellular products including dysregulated miRNAs, mRNAs and proteins as well as microbial by-products. Once internalized by neural cells, exosomes can functionally transfer the neurotoxic cargo to astrocytes and neurons causing neurodysfunction. (B) Normal intercellular communication in the brain mediated by exosomes. The release and uptake of exosomes by various cell types in the brain is part of normal brain communication. Astrocytes release exosomes enriched in heat shock proteins that serve a neuroprotective function during stress conditions. Exosomes shed by microglia, on the other hand, promote neurotransmission by stimulating ceramide and sphingosine syntheses. Oligodendrocyte-derived exosomes offer metabolic support to neurons in response to glutamate activation while neuronal exosomes regulate differentiation of the former. 
protein induces the release of exosomes enriched in miR$29 \mathrm{~b}$ which can impair neuronal function. The mechanism involves the functional transfer of miR-29b to neurons leading to the suppression of the neuroprotective protein platelet-derived growth factor (PDGF)-B expression. The expression of PDGF is also suppressed, and coupled to elevated levels of miR-29b, in the basal ganglia of the brains of simian immunodeficiency virus-infected macaques dependent on morphine, underscoring the possibility of exosomes mediating the neuropathology.

HIV-infected cells can also release the TAR RNA packaged into exosomes [26]. These exosomes are proposed to increase the susceptibility of the recipient cells, such as astrocytes, to HIV infection by the interference of host gene expression caused by 3'TAR-miRNA.

Prion disease Prion diseases are infectious neurodegenerative disorders associated with the accumulation of an abnormally folded isoform of the prion protein (PrP), scrapie (PrPSc), considered as the infectious agent. The misfolded protein can induce conformational conversion of cellular prion protein into its pathogenic isoform by a protein-only template-directed mechanism. The disease, often fatal in nature includes CJD in humans, scrapie in sheep, and bovine spongiform encephalopathy in cows. It is characterized by massive neuronal loss leading to the formation of large spongiform vacuoles in the brain.

Although conditioned media from prion-infected neurons can spread infection to uninfected cells, the mechanism for such dissemination remained elusive for many years. A pioneering study by Fevrier et al. [43] demonstrated that PsPSc associates with neuronal exosomes, thereby bypassing the need for cell-to-cell contact. Interestingly, these exosomes were shown to infect not only uninfected recipient cells but also non-neuronal cells [47]. Exosome-associated PrP is processed by a distinct pathway that involves $\mathrm{N}$-terminal modification of the protein and selective loading of PrP glycoforms for incorporation into the vesicles [47].

Another significant observation in regard to the role of exosomes in the pathogenesis of prion disease was made by Bellingham and colleagues [19]. They demonstrated that exosomes secreted by prion-infected neuronal cells have significantly altered miRNA content including elevated expression of several miRNAs associated with neurological disorders such as miRs-29b, 128a and 146a. Alteration of exosomal miRNA content can influence the functioning of the recipient cell by dysregulating the expression of potentially important genes.

\section{Exosomes and neurodegeneration}

Alzheimer's disease (AD) AD is the most common form of age-associated dementia in humans [48]. It is characterized by accumulation of extracellular amyloid
$\beta(\mathrm{A} \beta)$ plaques and intracellular neurofibrillary tangles of hyperphosphorylated tau protein that ultimately leads to slow and progressive loss of neurons. The $A \beta$ peptide is formed by the sequential proteolytic cleavage of the transmembrane amyloid precursor protein (APP) by two membrane-bound enzymes $\beta$-secretase and $\gamma$-secretase. Although several different species of $A \beta$ peptides are generated, the longer forms are particularly hydrophobic and prone to aggregation in extracellular $A \beta$ plaques [49]. The tau protein, on the other hand, is a microtubulestabilizing protein that is predominantly expressed in neurons and regulates axonal transport. Hyperphosphorylation of tau leads to its dissociation from microtubules and aggregation into insoluble fibers in neurons.

The roles of exosomes in mediating the pathogenesis of $\mathrm{AD}$ were initially associated with the nanovesicles serving as vehicles for the transport of the $A \beta$ peptides to the extracellular environment. A seminal study by Rajendran et al. [44] demonstrated that the cleavage of APP by $\beta$ secretase occurs in a specific subset of endosomes and is trafficked into MVBs from where it is released in association with exosomes. Interestingly, exosomal proteins such as Alix and flotillin-1 are found to accumulate around amyloid plaques in the brains of $\mathrm{AD}$ patients further underscoring the relevance of exosomes in spreading $A \beta$ [44]. Recently, amyloid peptides were shown to induce apoptosis in astrocytes by up-regulating the intracellular expression of the proapoptotic proteins, prostate apoptosis response 4 (PAR4) and ceramide [45]. Importantly, astrocytes exposed to the $\mathrm{A} \beta$ peptides could induce apoptosis in bystander astrocytes by the release of exosomes enriched in PAR4 and ceramide, suggesting that the vesicles could either functionally transfer the proteins to the recipient astrocytes or trigger a cascade of events ultimately leading to cell death. In addition to $A \beta$ peptides, exosomes also carry phosphorylated tau protein associated with neurodegeneration [50] and may be responsible for cell-to-cell spread of tau as has been reported previously [51]. Exosome-associated phosphotau is readily detected at elevated levels in the cerebrospinal fluid (CSF) samples of early AD patients and decreases as the disease progresses despite the increase in the overall level of the protein, possibly due to dissociation of tau from the exosome fraction.

Parkinson's disease After AD, Parkinson's disease (PD) is the most common neurodegenerative disorder affecting nearly $1 \%$ of the population over 50 years old [52]. Patients suffering from PD typically demonstrate movementrelated disorders such as resting tremor, and muscle rigidity and cognitive malfunction as the disease progresses. Elevated intracellular levels of aberrant conformations of $\alpha$-synuclein $(\alpha-$ Syn $)$, a presynaptic neuronal protein, areAccepted frequently associated with PD pathology. 
Similar to AD, exosomes have been shown to be involved in transporting $\alpha$-Syn to the extracellular environment and spreading the toxic oligomers to naïve neurons [53]. Uptake of exosomes loaded with $\alpha$-Syn has been shown to induce cell death in healthy neurons [46] further highlighting the potential of exosomes in the pathogenesis of neurodegenerative disorders. In addition to neurons, other cell types including astrocytes [54] have also been shown to internalize $\alpha$-Syn deposits released by pathologic neurons. The phenomenon is associated with the formation of inclusion bodies in the latter, as observed in the brains of PD patients [54] as well as initiation of an inflammatory response. Another interesting perspective to the role of exosomes in PD pathogenesis comes from the reports that mutations in several genes involved in the endocytic pathway such as leucine-rich receptor kinase 2 (LRRK2), and vacuolar sorting protein 35 (VPS35), are linked to PD [52]. LRRK2, for example, has been shown to regulate synaptic transmission and its overexpression is associated with suppression in synaptic vesicle endocytosis and exocytosis in neurons [55]. Additionally, a mutation in LRRK2 leads to an abnormal increase in the number of morphologically distinct MVBs [56]. Formation of a large number of MVBs could potentially lead to the accumulation of exosomes enriched in the toxic form of $\alpha$-Syn and spread the disease to neighboring cells upon release.

\section{Impact of peripheral inflammation on the CNS via exosomes}

Often, conditions associated with inflammation in the periphery impact brain function. For instance, untreated HIV infection is associated with neurocognitive impairment in over $50 \%$ of infected subjects $[57,58]$. Coinfection with hepatitis $\mathrm{C}$ virus ( $\mathrm{HCV}$ ) worsens neurological functioning regardless of HIV infection status [59-61]. Subjects with other inflammatory diseases such as systemic lupus erythematosus (SLE) [62] and rheumatoid arthritis (RA) [63] have also been shown to exhibit a high frequency of neurological disturbances. Interestingly, all the above stated disorders are associated with a peripheral type I IFN profile. While no direct correlative analysis has been performed to assess the relationship between peripheral activation and neurodysfunction in SLE and RA despite the high frequency of occurrence, our lab recently showed that the activation state of the circulating monocytes in $\mathrm{HIV} / \mathrm{HCV}$ coinfection correlates with worsening neurocognitive symptoms $[62,63,56]$.

Circulating monocytes traffic across the blood-brain barrier (BBB) as part of a normal physiological process to replenish the perivascular macrophages. However, during specific inflammatory conditions, a subset of activated monocytes migrate across the $\mathrm{BBB}$ at a much greater frequency and mediate events that ultimately lead to neural cell dysfunction [64]. In the context of untreated HIV infection, such transmigration is widely associated with spread of infection to the CNS, and release of neurotoxic pro-inflammatory cytokines from activated monocytes [65]. However, in the post-antiretroviral therapy (ART) era, neurocognitive impairment continues to persist and may be attributed to other mechanisms beside active viral infection [66-71]. The incidence of impairment is worsened during coinfection with HCV, a classical hepatotropic virus. While some studies have suggested that HIV can establish a silent reservoir in the monocytes despite successful viremic control, virus can be intermittently activated and contribute to HAND [65,72,73]. The occurrence of neurocognitive difficulties in certain non-infectious, inflammatory autoimmune disorders affecting the periphery however suggests that perhaps other mechanism (s) may also contribute to brain dysfunction (Figure 2).

Primary human monocytes have been shown to shed exosomes in vitro as well as in vivo [5,21]. In fact, the majority of the extracellular vesicles found to circulate in the body are shed by platelets and mononuclear cells [5]. Inflammatory signals from the environment can trigger a change in the gene expression and miRNA profile of a cell as well as in the exosomes shed by it. Given that cells release exosomes under both physiological as well as pathological conditions, monocyte-derived vesicles could serve as a vehicle to transport neurotoxic cargo to neural cells or alternatively trigger several signaling pathways by virtue of ligands and receptors on the exosomal surface [74]. Dysregulated miRNAs, or mRNA transcripts packaged into exosomes could be functionally delivered to neural cells and disrupt an array of pathways within the cell, ultimately causing disturbances in brain function. In addition, microbes that infect and replicate in monocyte/macrophages, for instance HIV, may release viral proteins or genomic products in exosomes and elicit an inflammatory response in recipient neural cells. This phenomenon has been shown to occur in T cells infected with HIV $[18,26]$ as well as HCVinfected hepatoma cells [75].

While monocyte/macrophages-derived exosomes can function as a 'Trojan horse', exosomes in circulation can also migrate across the $\mathrm{BBB}$ and exert a biological effect on neural cells by internalizing the vesicles and releasing exosomes in the CNS, as suggested by AlvarezErviti et al. [76].

\section{Exosomes for treating neuroinflammatory disorders}

One of the major hurdles in treating neuroinflammatory disorders has been the lack of an optimized delivery strategy that allows the drug to cross the BBB. Exosomes have the potential to serve as the ideal drug delivery vehicle' owing to their desirable properties such as low immunogenicity, ability to effectively transport a range 
of biomolecules and interact with a host of target cells, and importantly, amenability to manipulation for personalized medicine.

The concept that exosomes can be packaged with therapeutic agents and used for treating inflammatory conditions in vivo was first demonstrated by Sun et al. [77]. The study showed that exosomes loaded with curcumin, an anti-inflammatory naturally-occurring polyphenol, not only increased the bioavailability and stability of the compound in vivo, but also significantly improved survival in lipopolysaccharide (LPS)-induced septicemia. Building on this finding, Zhang et al. [78] later showed that LPSinduced brain inflammation in mice could be alleviated by intranasal administration of curcumin-loaded exosomes. The exosomes were selectively internalized by microglial cells and subsequently induced apoptosis in the activated recipient cells.

Exosomes can be manipulated ex vivo to carry not just therapeutic drugs but also short interfering RNAs (siRNAs) targeted against specific genes in the brain [79]. siRNAs are small non-coding RNA sequences that suppress gene expression by degrading the complementary mRNA transcript. Alvarez-Erviti et al. [76] demonstrated that exosomes from self-derived dendritic cells suppressed target genes in the brain by the delivery of siRNA to neurons, microglia and oligodendrocytes. The exosomes were targeted specifically to neural cells by transfection of dendritic cells with Lamp2b, an exosomal membrane protein fused to a rabies glycoprotein peptide. The authors also showed that exosomes could be loaded directly with siRNAs by electroporation and gene expression could be silenced in the CNS by intravenous injection of the vesicles. The latter observation suggests that exosomes in the periphery can cross the $\mathrm{BBB}$ and regulate brain function. Thus, exosomes have the potential to serve as a non-invasive intervention for the successful delivery of therapeutic agents to the brain.

Although the proof-of-concept studies are very encouraging, we are only beginning to understand the potential of exosomes as a viable therapeutic intervention for several hard-to-treat medical conditions. A few key considerations for the development of exosome-based therapies to treat neurological disorders are likely to revolve around: 1) specificity to achieve targeted delivery, 2) bioavailability and half-life of the exosomes in vivo in order to determine frequency of administration, 3) site of exosome administration and 4) potential toxicity associated with non-targeted effects.

\section{Exosomes as biomarkers for neuroinflammation}

Changes in the cellular environment often impact the content of exosomes shed by the cell. This phenomenon has the potential to extend the application of these nanovesicles as biomarkers for various pathological conditions wherein specific proteins/mRNAs and/or miRNAs that are altered in a diseased state can be detected in exosomes for early diagnosis. Indeed, Banigan et al. [35] recently showed that exosomal miRNAs recovered from postmortem prefrontal cortices of subjects diagnosed with schizophrenia and bipolar disorders were different from matched controls. Brain tissue samples from schizophrenic patients had significantly elevated levels of exosomal miR-497 while those from bipolar disorder had upregulation of miR-29c. Future studies focused on identifying disease-associated exosomal miRNAs in the CSF of living patients will perhaps validate the utility of exosomes to serve as biomarkers in schizophrenia and bipolar disorder. Apart from exosomal miRNAs, mRNA transcripts differentially packaged into exosomes released from diseased cells have also been proposed as biomarker candidates. Skog et al. [80] demonstrated that subjects with glioblastoma had detectable levels of vesicleassociated epidermal growth factor receptor (EGFRvIII) transcript in the serum that could be amplified by RTPCR. No amplification of the transcript was detected in vesicles isolated from healthy subjects. Interestingly, this variant of EGFR is specific to tumors and its specific detection only in vesicles isolated from cancer patients makes this transcript a good biomarker candidate.

\section{Conclusions}

The relevance of exosomes in the pathogenesis of several CNS disorders has only begun to be explored. Given their ability to mediate intercellular communication between cells, it is not surprising that exosomes represent one of the key players in transporting neurotoxic cargo and disseminating disease in the brain. Nevertheless, the potential of exosomes to be manipulated for the transport of therapeutic agents has generated heightened interest in the field, as these vesicles are capable of circumventing the major hurdles that are associated with the delivery of drugs across the BBB.

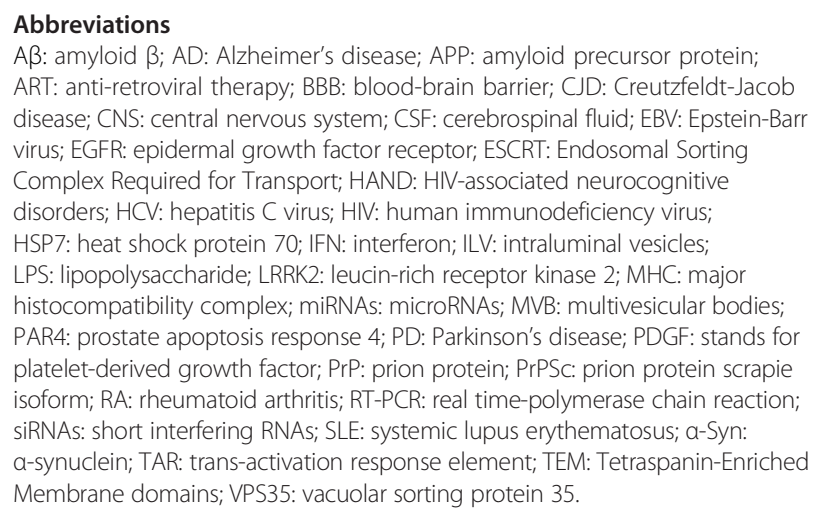

Competing interests

The authors declare that they have no competing interests. 


\section{Authors' contributions}

Both AG and LP contributed to the writing of this manuscript. Both authors read and approved the final manuscript.

\section{Acknowledgements}

We thank Dr. Bing Sun for assistance in preparing the figures. This publication was supported by NIH grant RO1 MH085538 (LP).

\section{Author details}

${ }^{1}$ Department of Microbiology and Immunology, Drexel University College of Medicine, 245 North 15th Street, Philadelphia, PA 19102, USA. ²Departments of Laboratory Medicine and Medicine, San Francisco and Veterans Affairs Medical Center, University of California, 4150 Clement St (113A), San Francisco, CA 94121, USA.

Received: 14 February 2014 Accepted: 17 March 2014 Published: 3 April 2014

\section{References}

1. Mathivanan S, Ji H, Simpson RJ: Exosomes: extracellular organelles important in intercellular communication. J Proteomics 2010, 73(10):1907-1920.

2. Trajkovic K, Hsu C, Chiantia S, Rajendran L, Wenzel D, Wieland F, Schwille P, Brugger B, Simons M: Ceramide triggers budding of exosome vesicles into multivesicular endosomes. Science 2008, 319(5867):1244-1247.

3. Sarkar A, Mitra S, Mehta S, Raices R, Wewers MD: Monocyte derived microvesicles deliver a cell death message via encapsulated caspase-1. PLoS One 2009, 4(9):e7140.

4. Zhang Y, Liu D, Chen X, Li J, Li L, Bian Z, Sun F, Lu J, Yin Y, Cai X, Sun Q, Wang K, Ba Y, Wang Q, Wang D, Yang J, Liu P, Xu T, Yan Q, Zhang J, Zen K. Zhang CY: Secreted monocytic miR-150 enhances targeted endothelial cell migration. Mol Cell 2010, 39(1):133-144.

5. Hunter MP, Ismail N, Zhang X, Aguda BD, Lee EJ, Yu L, Xiao T, Schafer J, Lee ML, Schmittgen TD, Nana-Sinkam SP, Jarjoura D, Marsh CB: Detection of microRNA expression in human peripheral blood microvesicles. PLoS One 2008, 3(11):e3694.

6. Thery C, Zitvogel L, Amigorena S: Exosomes: composition, biogenesis and function. Nat Rev Immunol 2002, 2(8):569-579.

7. Lee Y, El Andaloussi S, Wood MJ: Exosomes and microvesicles: extracellular vesicles for genetic information transfer and gene therapy. Hum Mol Genet 2012, 21(R1):R125-R134.

8. Raposo G, Stoorvogel W: Extracellular vesicles: exosomes, microvesicles, and friends. J Cell Biol 2013, 200(4):373-383.

9. Hannafon BN, Ding WQ: Intercellular communication by exosome-derived microRNAs in cancer. Int J Mol Sci 2013, 14(7):14240-14269.

10. Bobrie A, Colombo M, Raposo G, Thery C: Exosome secretion: molecular mechanisms and roles in immune responses. Traffic 2011, 12(12):1659-1668.

11. Hemler ME: Targeting of tetraspanin proteins - potential benefits and strategies. Nat Rev Drug Discov 2008, 7(9):747-758.

12. Rana S, Zoller M: Exosome target cell selection and the importance of exosomal tetraspanins: a hypothesis. Biochem Soc Trans 2011, 39(2):559-562.

13. Hislop JN, von Zastrow M: Role of ubiquitination in endocytic trafficking of G-protein-coupled receptors. Traffic 2011, 12(2):137-148.

14. Ohno S, Ishikawa A, Kuroda M: Roles of exosomes and microvesicles in disease pathogenesis. Adv Drug Deliv Rev 2013, 65(3):398-401.

15. Utsugi-Kobukai S, Fujimaki H, Hotta C, Nakazawa M, Minami M: MHC class I-mediated exogenous antigen presentation by exosomes secreted from immature and mature bone marrow derived dendritic cells. Immunol Lett 2003, 89(2-3):125-131.

16. Luketic L, Delanghe J, Sobol PT, Yang P, Frotten E, Mossman KL, Gauldie J, Bramson J, Wan Y: Antigen presentation by exosomes released from peptide-pulsed dendritic cells is not suppressed by the presence of active CTL. J Immunol 2007, 179(8):5024-5032

17. Ji H, Greening DW, Barnes TW, Lim JW, Tauro BJ, Rai A, Xu R, Adda C, Mathivanan S, Zhao W, Xue Y, Xu T, Zhu HJ, Simpson RJ: Proteome profiling of exosomes derived from human primary and metastatic colorectal cancer cells reveal differential expression of key metastatic factors and signal transduction components. Proteomics 2013, 13(10-11):1672-1686.

18. Lenassi M, Cagney G, Liao M, Vaupotic T, Bartholomeeusen $\mathrm{K}$, Cheng $\mathrm{Y}$, Krogan NJ, Plemenitas A, Peterlin BM: HIV Nef is secreted in exosomes and triggers apoptosis in bystander CD4+ T cells. Traffic 2010, 11(1):110-122.
19. Bellingham SA, Coleman BM, Hill AF: Small RNA deep sequencing reveals a distinct miRNA signature released in exosomes from prion-infected neuronal cells. Nucleic Acids Res 2012, 40(21):10937-10949.

20. Hu G, Yao H, Chaudhuri AD, Duan M, Yelamanchili SV, Wen H, Cheney PD, Fox HS, Buch S: Exosome-mediated shuttling of microRNA-29 regulates HIV Tat and morphine-mediated neuronal dysfunction. Cell Death Dis 2012, 3:e381.

21. Ismail N, Wang Y, Dakhlallah D, Moldovan L, Agarwal K, Batte K, Shah P, Wisler J, Eubank TD, Tridandapani S, Paulaitis ME, Piper MG, Marsh CB: Macrophage microvesicles induce macrophage differentiation and miR-223 transfer. Blood 2013, 121(6):984-995.

22. Xin H, Li Y, Buller B, Katakowski M, Zhang Y, Wang X, Shang X, Zhang ZG, Chopp M: Exosome-mediated transfer of miR-133b from multipotent mesenchymal stromal cells to neural cells contributes to neurite outgrowth. Stem Cells 2012, 30(7):1556-1564.

23. Li L, Zhu D, Huang L, Zhang J, Bian Z, Chen X, Liu Y, Zhang CY, Zen K: Argonaute 2 complexes selectively protect the circulating microRNAs in cell-secreted microvesicles. PLoS One 2012, 7(10):e46957.

24. Gibbings DJ, Ciaudo C, Erhardt M, Voinnet O: Multivesicular bodies associate with components of miRNA effector complexes and modulate miRNA activity. Nat Cell Biol 2009, 11(9):1143-1149.

25. Pegtel DM, Cosmopoulos K, Thorley-Lawson DA, van Eijndhoven MA, Hopmans ES, Lindenberg JL, de Gruijl TD, Wurdinger T, Middeldorp JM: Functional delivery of viral miRNAs via exosomes. Proc Natl Acad Sci U S A 2010, 107(14):6328-6333.

26. Narayanan A, lordanskiy $S$, Das $R$, Van Duyne $R$, Santos $S$, Jaworski E, Guendel I, Sampey G, Dalby E, Iglesias-Ussel M, Popratiloff A, Hakami R, Kehn-Hall K, Young M, Subra C, Gilbert C, Bailey C, Romerio F, Kashanchi F: Exosomes derived from HIV-1-infected cells contain trans-activation response element RNA. J Biol Chem 2013, 288(27):20014-20033.

27. Valadi H, Ekstrom K, Bossios A, Sjostrand M, Lee JJ, Lotvall JO: Exosome-mediated transfer of mRNAs and microRNAs is a novel mechanism of genetic exchange between cells. Nat Cell Biol 2007, 9(6):654-659.

28. Batagov AO, Kurochkin IV: Exosomes secreted by human cells transport largely mRNA fragments that are enriched in the 3 '-untranslated regions. Biol Direct 2013, 8:12.

29. Escrevente C, Keller S, Altevogt P, Costa J: Interaction and uptake of exosomes by ovarian cancer cells. BMC Cancer 2011, 11:108.

30. Morelli AE, Larregina AT, Shufesky WJ, Sullivan ML, Stolz DB, Papworth GD, Zahorchak AF, Logar AJ, Wang Z, Watkins SC, Falo LD Jr, Thomson AW: Endocytosis, intracellular sorting, and processing of exosomes by dendritic cells. Blood 2004, 104(10):3257-3266.

31. Feng D, Zhao WL, Ye YY, Bai XC, Liu RQ, Chang LF, Zhou Q, Sui SF: Cellular internalization of exosomes occurs through phagocytosis. Traffic 2010 11(5):675-687.

32. Fitzner D, Schnaars M, van Rossum D, Krishnamoorthy G, Dibaj P, Bakhti M, Regen T, Hanisch UK, Simons M: Selective transfer of exosomes from oligodendrocytes to microglia by macropinocytosis. J Cell Sci 2011, 124(Pt 3):447-458.

33. Svensson KJ, Christianson HC, Wittrup A, Bourseau-Guilmain E, Lindqvist E, Svensson LM, Morgelin M, Belting M: Exosome uptake depends on ERK1/ 2-heat shock protein 27 signaling and lipid Raft-mediated endocytosis negatively regulated by caveolin-1.J Biol Chem 2013, 288(24):17713-17724.

34. Street JM, Barran PE, Mackay CL, Weidt S, Balmforth C, Walsh TS, Chalmers RT, Webb DJ, Dear JW: Identification and proteomic profiling of exosomes in human cerebrospinal fluid. J Trans/ Med 2012, 10:5.

35. Banigan MG, Kao PF, Kozubek JA, Winslow AR, Medina J, Costa J, Schmitt A, Schneider A, Cabral H, Cagsal-Getkin O, Vanderburg CR, Delalle I: Differential expression of exosomal microRNAs in prefrontal cortices of schizophrenia and bipolar disorder patients. PLOS One 2013, 8(1):e48814.

36. Bakhti M, Winter C, Simons M: Inhibition of myelin membrane sheath formation by oligodendrocyte-derived exosome-like vesicles. J Biol Chem 2011, 286(1):787-796.

37. Fruhbeis $C$, Frohlich D, Kuo WP, Amphornrat J, Thilemann S, Saab AS, Kirchhoff F, Mobius W, Goebbels S, Nave KA, Schneider A, Simons M, Klugmann M, Trotter J, Kramer-Albers EM: Neurotransmitter-triggered transfer of exosomes mediates oligodendrocyte-neuron communication. PLOS Biol 2013, 11(7):e1001604.

38. Wang S, Cesca F, Loers G, Schweizer M, Buck F, Benfenati F, Schachner M, Kleene R: Synapsin I is an oligomannose-carrying glycoprotein, acts as an oligomannose-binding lectin, and promotes neurite outgrowth and 
neuronal survival when released via glia-derived exosomes. J Neurosci 2011, 31(20):7275-7290.

39. Antonucci F, Turola E, Riganti L, Caleo M, Gabrielli M, Perrotta C, Novellino L, Clementi E, Giussani P, Viani P, Matteoli M, Verderio C: Microvesicles released from microglia stimulate synaptic activity via enhanced sphingolipid metabolism. EMBO J 2012, 31(5):1231-1240.

40. Taylor AR, Robinson MB, Gifondorwa DJ, Tytell M, Milligan CE: Regulation of heat shock protein 70 release in astrocytes: role of signaling kinases. Dev Neurobiol 2007, 67(13):1815-1829.

41. Tytell M: Release of heat shock proteins (Hsps) and the effects of extracellular Hsps on neural cells and tissues. Int J Hyperthermia 2005, 21(5):445-455.

42. Lopez-Verrilli MA, Picou F, Court FA: Schwann cell-derived exosomes enhance axonal regeneration in the peripheral nervous system. Glia 2013, 61(11):1795-1806.

43. Fevrier B, Vilette D, Archer F, Loew D, Faigle W, Vidal M, Laude H, Raposo G: Cells release prions in association with exosomes. Proc Natl Acad Sci U S A 2004, 101(26):9683-9688

44. Rajendran L, Honsho M, Zahn TR, Keller P, Geiger KD, Verkade P, Simons K: Alzheimer's disease beta-amyloid peptides are released in association with exosomes. Proc Natl Acad Sci U S A 2006, 103(30):11172-11177.

45. Wang G, Dinkins M, He Q, Zhu G, Poirier C, Campbell A, Mayer-Proschel M, Bieberich E: Astrocytes secrete exosomes enriched with proapoptotic ceramide and prostate apoptosis response 4 (PAR-4): potential mechanism of apoptosis induction in Alzheimer disease (AD). J Biol Chem 2012, 287(25):21384-21395.

46. Emmanouilidou E, Melachroinou K, Roumeliotis T, Garbis SD, Ntzouni M, Margaritis LH, Stefanis L, Vekrellis K: Cell-produced alpha-synuclein is secreted in a calcium-dependent manner by exosomes and impacts neuronal survival. J Neurosci 2010, 30(20):6838-6851.

47. Vella LJ, Sharples RA, Lawson VA, Masters CL, Cappai R, Hill AF: Packaging of prions into exosomes is associated with a novel pathway of PrP processing. J Patho/ 2007, 211(5):582-590.

48. Avramopoulos D: Genetics of Alzheimer's disease: recent advances. Genome Med 2009, 1(3):34.

49. Murphy MP, LeVine $H$ 3rd: Alzheimer's disease and the amyloid-beta peptide. J Alzheimers Dis 2010, 19(1):311-323.

50. Saman S, Kim W, Raya M, Visnick Y, Miro S, Jackson B, McKee AC, Alvarez VE, Lee NC, Hall GF: Exosome-associated tau is secreted in tauopathy models and is selectively phosphorylated in cerebrospinal fluid in early Alzheimer disease. J Biol Chem 2012, 287(6):3842-3849.

51. Frost $B$, Jacks RL, Diamond MI: Propagation of tau misfolding from the outside to the inside of a cell. J Biol Chem 2009, 284(19):12845-12852.

52. Russo I, Bubacco L, Greggio E: Exosomes-associated neurodegeneration and progression of Parkinson's disease. Am J Neurodegener Dis 2012, 1(3):217-225.

53. Danzer KM, Kranich LR, Ruf WP, Cagsal-Getkin O, Winslow AR, Zhu L Vanderburg CR, McLean PJ: Exosomal cell-to-cell transmission of alpha synuclein oligomers. Mol Neurodegener 2012, 7:42.

54. Lee HJ, Suk JE, Patrick C, Bae EJ, Cho JH, Rho S, Hwang D, Masliah E, Lee SJ: Direct transfer of alpha-synuclein from neuron to astroglia causes inflammatory responses in synucleinopathies. J Biol Chem 2010, 285(12):9262-9272

55. Xiong Y, Coombes CE, Kilaru A, Li X, Gitler AD, Bowers WJ, Dawson VL, Dawson TM, Moore DJ: GTPase activity plays a key role in the pathobiology of LRRK2. PLoS Genet 2010, 6(4):e1000902.

56. Alegre-Abarrategui J, Wade-Martins R: Parkinson disease, LRRK2 and the endocytic-autophagic pathway. Autophagy 2009, 5(8):1208-1210.

57. Heaton RK, Franklin DR, Ellis RJ, McCutchan JA, Letendre SL, Leblanc S, Corkran SH, Duarte NA, Clifford DB, Woods SP, Collier AC, Marra CM, Morgello S, Mindt MR, Taylor MJ, Marcotte TD, Atkinson JH, Wolfson T, Gelman BB, McArthur JC, Simpson DM, Abramson I, Gamst A, Fennema-Notestine C, Jernigan TL, Wong J, Grant I: HIV-associated neurocognitive disorders before and during the era of combination antiretroviral therapy: differences in rates, nature, and predictors. J Neurovirol 2011, 17(1):3-16.

58. Boisse L, Gill MJ, Power C: HIV infection of the central nervous system: clinical features and neuropathogenesis. Neurol Clin 2008, 26(3):799-819.

59. Vivithanaporn P, Nelles K, DeBlock L, Newman SC, Gill MJ, Power C: Hepatitis C virus co-infection increases neurocognitive impairment severity and risk of death in treated HIV/AIDS. J Neurol Sci 2012, 312(1-2):45-51.
60. Hinkin $\mathrm{CH}$, Castellon SA, Levine AJ, Barclay TR, Singer EJ: Neurocognition in individuals co-infected with HIV and hepatitis C. J Addict Dis 2008, 27(2):11-17

61. Sun B, Abadjian L, Rempel H, Monto A, Pulliam L: Differential cognitive impairment in HCV coinfected men with controlled HIV compared to HCV monoinfection. J Acquir Immune Defic Syndr 2013, 62(2):190-196.

62. Mikdashi JA, Esdaile JM, Alarcon GS, Crofford L, Fessler BJ, Shanberg L, Brunner H, Gall V, Kalden JR, Lockshin MD, Liang MH, Roberts N Jr, Schneider M: Proposed response criteria for neurocognitive impairment in systemic lupus erythematosus clinical trials. Lupus 2007, 16(6):418-425.

63. Higgs BW, Liu Z, White B, Zhu W, White WI, Morehouse C, Brohawn P, Kiener PA, Richman L, Fiorentino D, Greenberg SA, Jallal B, Yao Y: Patients with systemic lupus erythematosus, myositis, rheumatoid arthritis and scleroderma share activation of a common type I interferon pathway. Ann Rheum Dis 2011, 70(11):2029-2036.

64. Williams DW, Eugenin EA, Calderon TM, Berman JW: Monocyte maturation, HIV susceptibility, and transmigration across the blood brain barrier are critical in HIV neuropathogenesis. J Leukoc Biol 2012, 91(3):401-415

65. Kusao I, Shiramizu B, Liang CY, Grove J, Agsalda M, Troelstrup D, Velasco VN, Marshall A, Whitenack N, Shikuma C, Valcour V: Cognitive performance related to HIV-1-infected monocytes. J Neuropsychiatry Clin Neurosci 2012, 24(1):71-80

66. Heaton RK, Clifford DB, Franklin DR Jr, Woods SP, Ake C, Vaida F, Ellis RJ, Letendre SL, Marcotte TD, Atkinson JH, Rivera-Mindt M, Vigil OR, Taylor MJ, Collier AC, Marra CM, Gelman BB, McArthur JC, Morgello S, Simpson DM, McCutchan JA, Abramson I, Gamst A, Fennema-Notestine C, Jernigan TL, Wong J, Grant I: HIV-associated neurocognitive disorders persist in the era of potent antiretroviral therapy: CHARTER Study. Neurology 2010, 75(23):2087-2096.

67. Clifford DB, Ances BM: HIV-associated neurocognitive disorder. Lancet Infect Dis 2013, 13(11):976-986.

68. Krstic D, Madhusudan A, Doehner J, Vogel P, Notter T, Imhof C, Manalastas A, Hilfiker M, Pfister S, Schwerdel C, Riether C, Meyer U, Knuesel I: Systemic immune challenges trigger and drive Alzheimer-like neuropathology in mice. J Neuroinflammation 2012, 9:151.

69. Esiri MM, Biddolph SC, Morris CS: Prevalence of Alzheimer plaques in AIDS. J Neurol Neurosurg Psychiatry 1998, 65(1):29-33.

70. Stanley LC, Mrak RE, Woody RC, Perrot LJ, Zhang S, Marshak DR, Nelson SJ, Griffin WS: Glial cytokines as neuropathogenic factors in HIV infection: pathogenic similarities to Alzheimer's disease. J Neuropathol Exp Neurol 1994, 53(3):231-238.

71. Rempel HC, Pulliam L: HIV-1 Tat inhibits neprilysin and elevates amyloid beta. AIDS 2005, 19(2):127-135.

72. Valcour VG, Shiramizu BT, Shikuma CM: HIV DNA in circulating monocytes as a mechanism to dementia and other HIV complications. J Leukoc Biol 2010, 87(4):621-626.

73. Valcour VG, Ananworanich J, Agsalda M, Sailasuta N, Chalermchai T, Schuetz A, Shikuma C, Liang CY, Jirajariyavej S, Sithinamsuwan P, Tipsuk S, Clifford DB, Paul R, Fletcher JL, Marovich MA, Slike BM, DeGruttola V, Shiramizu B: HIV DNA reservoir increases risk for cognitive disorders in CART-naive patients. PLoS One 2013, 8(7):e70164.

74. Anand PK: Exosomal membrane molecules are potent immune response modulators. Commun Integr Biol 2010, 3(5):405-408.

75. Dreux M, Garaigorta U, Boyd B, Decembre E, Chung J, Whitten-Bauer C, Wieland S, Chisari FV: Short-range exosomal transfer of viral RNA from infected cells to plasmacytoid dendritic cells triggers innate immunity. Cell Host Microbe 2012, 12(4):558-570.

76. Alvarez-Erviti L, Seow Y, Yin H, Betts C, Lakhal S, Wood MJ: Delivery of siRNA to the mouse brain by systemic injection of targeted exosomes. Nat Biotechnol 2011, 29(4):341-345.

77. Sun D, Zhuang X, Xiang X, Liu Y, Zhang S, Liu C, Barnes S, Grizzle W, Miller D, Zhang HG: A novel nanoparticle drug delivery system: the anti-inflammatory activity of curcumin is enhanced when encapsulated in exosomes. Mol Ther 2010, 18(9):1606-1614.

78. Zhuang X, Xiang X, Grizzle W, Sun D, Zhang S, Axtell RC, Ju S, Mu J, Zhang L, Steinman L, Miller D, Zhang HG: Treatment of brain inflammatory diseases by delivering exosome encapsulated anti-inflammatory drugs from the nasal region to the brain. Mol Ther 2011, 19(10):1769-1779. 
79. van den Boorn JG, Schlee M, Coch C, Hartmann G: SiRNA delivery with exosome nanoparticles. Nat Biotechnol 2011, 29(4):325-326.

80. Skog J, Wurdinger T, van Rijn S, Meijer DH, Gainche L, Sena-Esteves M, Curry WT Jr, Carter BS, Krichevsky AM, Breakefield XO: Glioblastoma microvesicles transport RNA and proteins that promote tumour growth and provide diagnostic biomarkers. Nat Cell Biol 2008, 10(12):1470-1476.

doi:10.1186/1742-2094-11-68

Cite this article as: Gupta and Pulliam: Exosomes as mediators of neuroinflammation. Journal of Neuroinflammation 2014 11:68.

\section{Submit your next manuscript to BioMed Central and take full advantage of:}

- Convenient online submission

- Thorough peer review

- No space constraints or color figure charges

- Immediate publication on acceptance

- Inclusion in PubMed, CAS, Scopus and Google Scholar

- Research which is freely available for redistribution 